\title{
ANALISIS KEPEMILIKAN JAMBAN KELUARGA DI DESA BANUA RANTAU WILAYAH KERJA PUSKESMAS BANUA LAWAS KABUPATEN TABALONG TAHUN 2019
}

\section{ANALYSIS OF FAMILY LATRINE OWNERSHIP IN BANUA RANTAU VILLAGE, WORKING AREA OF BANUA LAWAS PUSKESMAS TABALONG REGENCY IN 2019}

\author{
Meilya Farika Indah', Yeni Riza ${ }^{2}$, Kiki Amilia ${ }^{3}$ \\ 1,2,3Fakultas Kesehatan Masyarakat, Universitas Islam Kalimantan (UNISKA) MAB \\ Banjarmasin
}

Jl. Adhyaksa. No.2. Kota Banjarmasin, Kalimantan Selatan. Indonesia

*E-mail: meilyafarika1@gmail.com

\begin{abstract}
Nationally, there are $69,27 \%$ households that have access to sanitation, worth the percentage of households that have access to sanitation worthy of the lowest is Papua 33,75\%, Bengkulu 44,31\%, and East Nusa Tenggara 50,72\%. This study aims to analyzing the factors related to family latrine ownership in Banua Rantau village, sub-district Banua Lawas of, regency of Tabalong in 2019. This research is analytic survey study with cross sectional design using the primary data was collected from the responden of household. The data was analyzed by analytic and statitical test with chi square test with degree of confidence was 95\%. The result of statistic analysis indicates that there was a significant correlation between education $(p=0,000)$, the job $(p=0,000)$, the income $(p=0,000)$, and the knowledge $(p=0,000)$ with atrine ownership. It is recommended for sanitary officer in the working area of Banua Lawas Health Center to provide continuous health education on the importance of atrine ownership and environmental sanitation. It is expected that the Tabalong health department government to build a public latrine (communal latrine) as a means to defecate for the community have not been able to build latrines.
\end{abstract}

Keywords: Education; job; income; knowledge; latrine

\begin{abstract}
ABSTRAK
Secara nasional, terdapat 69,27\% rumah tangga yang memiliki akses terhadap sanitasi layak, persentase rumah tangga yang memiliki akses terhadap sanitasi layak terendah adalah Papua 33,75\%, Bengkulu 44,31\%, dan Nusa Tenggara Timur 50,72\%. Penelitian ini bertujuan untuk menganalisa faktor-faktor yang berhubungan dengan kepemilikan jamban keluarga di Desa Banua Rantau Wilayah Kerja Puskesmas Banua Lawas Kabupaten Tabalong Tahun 2019. Jenis penelitian survey analitik dengan desain cross sectional, menggunakan data primer yang diperoleh dari responden yaitu Kepala Keluarga. Data dianalisis secara analitik dan diuji secara statistik dengan uji Chi Square pada taraf kepercayaan 95\%. Hasil analisis statistik menunjukkan bahwa ada hubungan yang bermakna antara pendidikan $(p=0,000)$, pekerjaan $(p=0,000)$, penghasilan $(p=0,000)$, dan pengetahuan $(p=0,000)$ dengan kepemilikan jamban keluarga. Disarankan bagi petugas kesehatan lingkungan di wilayah kerja Puskesmas Banua Lawas agar meningkatkan penyuluhan kesehatan mengenai pentingnya kepemilikan jamban keluarga dan sanitasi lingkungan dan diharapkan kepada Dinas Kesehatan Kabupaten Tabalong agar membangun jamban umum (jamban komunal) sebagai sarana/ tempat untuk buang air besar bagi masyarakat yang belum mampu untuk membangun jamban keluarga.
\end{abstract}

Kata kunci: Pendidikan; pekerjaan; penghasilan; pengetahuan; jamban sehat 


\section{PENDAHULUAN}

Komitmen pemerintah dalam mewujudkan derajat kesehatan masyarakat, merupakan salah satu unsur penting dalam upaya peningkatkan Indeks Pembangunan Manusia (IPM) Bangsa Indonesia. Peningkatan derajat kesehatan yang optimal tersebut diselenggarakan melalui pendekatan, pemeliharaan, peningkatan kesehatan (promotif), pencegahan penyakit (preventif), penyembuhan penyakit (kuratif), dan pemulihan kesehatan (rehabilitatif). Salah satu program dalam peningkatan derajat kesehatan tersebut adalah program penggunaan jamban sehat. Salah satu upaya untuk mencegah berkembangnya penyakit dan menjaga lingkungan menjadi bersih dan sehat dengan cara membangun jamban di setiap rumah. Karena jamban merupakan salah satu kebutuhan pokok manusia. Penggunaan jamban yang disertai partisipasi keluarga akan baik, bila didukung oleh beberapa faktor. Diantaranya faktor yang berasal dari dalam diri individu yang disebut faktor internal seperti pendidikan, pengetahuan, sikap, tindakan atau kebiasaan, pekerjaan, pendapatan, penghasilan, jenis kelamin, umur, suku, dan sebagainya. Adapun faktor eksternal seperti fasilitas jamban baik meliputi jenisnya, kebersihannya, kondisinya, ketersediaannya termasuk kecukupan air bersihnya dan pengaruh lingkungan seperti penyuluhan oleh petugas kesehatan termasuk tokoh adat dan agama tentang penggunaan jamban sehat (1).

Berdasarkan hasil penelitian Yance (2006) tentang hubungan pengetahuan, tingkat pendidikan, dan status ekonomi dengan ketersediaan jamban keluarga di Desa Cidenok wilayah kerja UPTD Puskesmas Sumberjaya Kabupaten Majalengka diketahui bahwa ada hubungan antara pengetahuan, tingkat pendidikan, dan status ekonomi dengan ketersediaan jamban keluarga di Desa Cidenok wilayah kerja UPTD Puskesmas Sumberjaya Kabupaten Majalengka (2). Hasil penelitian juga menunjukkan bahwa determinan yang paling berpengaruh terhadap perilaku kesehatan yaitu kepemilikan jamban sebagai faktor pemungkin (enabling) dalam hal penggunaan jamban di Desa Sukamurni di Kabupaten Bekasi. Salah satu fasilitas kesehatan keluarga yang memungkinkan anggota keluarga menggunakan jamban untuk sarana buang air besar yaitu ketersedian adanya jamban (3).
Berdasarkan hal yang terungkap di Desa Banua Rantau adalah adanya persepsi bahwa jamban keluarga belum dirasakan oleh sebagian besar masyarakat sebagai kebutuhan yang mendesak. Berdasarkan hasil observasi awal kondisi di lapangan, sungai untuk tempat buang air besar, mandi, mencuci, yang digunakan masyarakat berada di depan rumah, hanya memerlukan waktu sedikit untuk pergi ke sungai tersebut, hal tersebut mungkin menjadikan masyarakat terbiasa untuk buang air besar di sungai. Penelitian ini bertujuan untuk menganalisis kepemilikan jamban sehat di Desa Banua Rantau Wilayah Kerja Puskesmas Banua Lawas Kabupaten Tabalong serta faktor-faktor yang berhungan dengan kepemilikan jamban sehat tersebut. Faktor-faktor yang diteliti antara lain tingkat pendidikan, status pekerjaan, tingkat penghasilan, dan pengetahuan.

\section{BAHAN DAN METODE}

Penelitian ini menggunakan desain survey analitik, dengan pendekatan Cross Sectional. Populasi dalam penelitian ini adalah semua Kepala Keluarga di Desa Banua Rantau Kecamatan Banua Lawas Kabupaten Tabalong yang berjumlah 447 Kepala Keluarga. Pengambilan sampel menggunakan rumus Lemeshow (1997), diperoleh sampel sebanyak 80 Kepala Keluarga. Teknik pengambilan sampel dengan proportional random sampling. Instrumen dalam penelitian ini menggunakan angket atau kuesioner untuk meilihat tingkat pendidikan, status pekerjaan, tingkat penghasilan, dan pengetahuan, sedangkan lembar observasi dalam bentuk checklist untuk melihat jamban keluarga yang dimiliki responden masuk kategori jamban sehat atau jamban tidak sehat. Analisis data berupa univariat dan bivariat dengan menggunakan uji chisquare dengan tingkat kepercayaan 95\% $(p<0,05)(4)$.

\section{HASIL DAN PEMBAHASAN}

\section{Analisis Univariat}

Tabel 1. Karakteristik Responden

\begin{tabular}{lcc}
\hline \multicolumn{1}{c}{ Variabel } & $\mathrm{n}$ & $\%$ \\
\hline Pendidikan & & \\
Rendah & 52 & 65 \\
Tinggi & 80 & 35 \\
& & \\
\hline
\end{tabular}




\begin{tabular}{lcc} 
Status Pekerjaan & 55 & 68,8 \\
Informan & 25 & 31,3 \\
Formal & & \\
Pendidikan & 47 & 58,8 \\
Rendah & 33 & 41,3 \\
Tinggi & & \\
Kepemilikan Jamban & 52 & 65 \\
Tidak Memiliki Jamban & 9 & 11,3 \\
Jamban Tidak Sehat & 19 & 23,8 \\
Jamban Sehat & & \\
Total & $\mathbf{8 0}$ & $\mathbf{1 0 0 , 0}$ \\
\hline
\end{tabular}

Berdasarkan tabel 1 dapat dilihat dari 80 responden sebanyak $52(65 \%)$ responden dengan tingkat pendidikan rendah, dan responden dengan tingkat pendidikan tinggi sebanyak 28 (35\%) responden. Hal yang ditemukan ketika melakukan penelitian, responden yang berpendidikan rendah sebanyak 53 (65\%) responden, banyak yang memberikan alasan yang sama mengapa memiliki pendidikan rendah, hal tersebut dikarenakan jauhnya tempat sekolah dan kurangnya biaya untuk sekolah maka responden tidak bisa melajutkan untuk bersekolah ke jenjang yang lebih tinggi. Banyak responden yang menceritakan kalau dari kecil sudah ikut membantu orangtuanya untuk mencari uang, seperti dengan membantu mencari ikan, ikut ke lahan pertanian, dan berjualan ke pasar.

Sedangkan untuk variabel status pekerjaan sebanyak $55(68,8 \%)$ responden memiliki status pekerjaan informal, dan sebanyak 25 (31,3\%) responden memiliki status pekerjaan formal. Hal yang ditemukan ketika melakukan penelitian, dari 55 $(68,8 \%)$ responden yang memiliki status pekerjaan dibidang sektor informal responden tersebut hanya memiliki tingkat pendidikan rendah, sehingga sulit untuk mendapatkan pekerjaan formal seperti menjadi karyawan perusahaan ataupun menjadi pegawai negri sipil yang syaratnya harus memiliki ijazah tinggi. Sebagian besar responden yang bekerja dibidang sektor informal adalah sebagai petani (petani sawah, petani karet, dan petani sayuran).

Untuk variabel penghasila, dapat dilihat bahwa dari 80 responden sebanyak 47 (58,8\%) responden memiliki tingkat penghasilan rendah yaitu lebih kecil dari UMK Kabupaten Tabalong tahun 2019 (Rp. 2.739.000,-), sedangkan 33 (41,3\%) responden memiliki tingkat penghasilan tinggi yaitu lebih dari UMK Kabupaten Tabalong tahun 2019 (Rp. 2.739.000,-). Hal yang ditemukan ketika melakukan penelitian, tingginya persentase responden yang memiliki tingkat penghasilan rendah dibawah Upah Minimum Kabupaten Tabalong 2019 (Rp. 2.739.000,-) dikarenakan pekerjaan responden sebagian besar hanyalah bertani, dari hasil bertani responden hanya mendapatkan uang Rp. 1.000.000,- sampai dengan Rp. 2.000.000,- setiap bulannya, yang hanya cukup untuk memenuhi kebutuhan hidup sehari-hari dan kalaupun ada uang sisa akan disimpan untuk keperluan berobat atau untuk kebutuhan mendesak lainnya. Dan untuk variabel pengetahuan dilihat bahwa dari 80 responden sebanyak 48 (60\%) responden memiliki pengetahuan kurang, dan sebanyak $32(40 \%)$ responden memiliki pengetahuan baik. Persentase responden dengan pengetahun kurang lebih tinggi dibandingkan dengan responden dengan pengetahuan baik, hal yang ditemukan peneliti ketika melakukan penelitian, karena kurangnya pendidikan dari responden, maka sulit untuk memahami pertanyaan yang diberikan mengenai pengertian jamban, penyakit yang ditimbulkan oleh tinja, manfaat jamban, jarak penampungan tinja terhadap air bersih, serta jenis jamban keluarga yang baik.

Serta untuk variabel kepemilikan jamban, dapat dilihat bahwa dari 80 responden sebanyak 52 (65\%) responden tidak memiliki jamban, 9 (11,3\%) responden memiliki jamban tidak sehat, dan 19 $(26,2 \%)$ responden memiliki jamban sehat. Hal yang ditemukan ketika melakukan penelitian yaitu responden yang tidak memiliki jamban kebanyakan memberikan alasan karena tidak adanya biaya yang cukup sehingga mereka tidak bisa untuk membangun jamban yang sesuai dengan syarat kesehatan.. Dari $9(11,3 \%)$ jamban keluarga yang masuk kategori jamban tidak sehat 7 (25\%) jamban tersebut memiliki penerangan dan ventilasi yang kurang, 5 (17,9\%) jamban tidak memiliki air, sabun, dan alat pembersih, dan 5 (17,9\%) jamban tersebut berbau. Padahal, Desa Banua Rantau hanya berjarak 6 kilometer dari kota Kelua, dan akses jalan menuju desa tersebut sangat nyaman. Maka sangat disayangkan mengapa desa tersebut angka kepemilikan jamban keluarganya masih rendah. 


\section{Analisis Bivariat}

Tabel 2. Hubungan Tingkat Pendidikan, Status Pekerjaan, Penghasilan Dan Pengetahuan Di Desa Banua Rantau Wilayah Kerja Puskesmas Banua Lawas Kabupaten Tabalong Tahun 2019

\begin{tabular}{|c|c|c|c|c|c|c|c|c|c|}
\hline \multirow{3}{*}{ Variabel } & \multicolumn{6}{|c|}{ Kepemilikan Jamban Keluarga } & \multirow{2}{*}{\multicolumn{2}{|c|}{ Total }} & \multirow{3}{*}{ P-Value } \\
\hline & \multicolumn{2}{|c|}{$\begin{array}{c}\text { Tidak } \\
\text { Memiliki } \\
\text { Jamban }\end{array}$} & \multicolumn{2}{|c|}{$\begin{array}{c}\text { Memiliki } \\
\text { Jamban } \\
\text { Sehat }\end{array}$} & \multicolumn{2}{|c|}{$\begin{array}{c}\text { Memiliki } \\
\text { Jamban Sehat }\end{array}$} & & & \\
\hline & $\mathbf{n}$ & $\%$ & $\mathbf{n}$ & $\%$ & $\mathbf{n}$ & $\%$ & $\mathbf{n}$ & $\%$ & \\
\hline \multicolumn{10}{|l|}{ Pendidikan } \\
\hline Rendah & 41 & 51,3 & 6 & 7,5 & 5 & 6.3 & 52 & 100,0 & 0,000 \\
\hline Tinggi & 11 & 13,8 & 3 & 3,8 & 14 & 17,5 & 28 & 100,0 & \\
\hline \multicolumn{10}{|l|}{ Status Pekerjaan } \\
\hline Informal & 44 & 55,0 & 7 & 8,8 & 4 & 5,0 & 55 & 100,0 & 0,000 \\
\hline Formal & 8 & 10,0 & 2 & 2,5 & 15 & 18,8 & 25 & 100,0 & \\
\hline \multicolumn{10}{|l|}{ Penghasilan } \\
\hline Rendah & 41 & 51,3 & 3 & 3,8 & 3 & 3,8 & 47 & 100,0 & 0,000 \\
\hline Tinggi & 11 & 13,8 & 6 & 7,5 & 16 & 20,0 & 33 & 100,0 & \\
\hline \multicolumn{10}{|l|}{ Pengetahuan } \\
\hline Kurang & 43 & 53,8 & 3 & 3,8 & 2 & 2,5 & 48 & 100,0 & 0,000 \\
\hline Baik & 9 & 11,3 & 6 & 7,5 & 17 & 21,3 & 32 & 100,0 & \\
\hline
\end{tabular}

\section{PEMBAHASAN}

Hubungan Tingkat Pendidikan Dengan Kepemilikan Jamban Keluarga di Desa Banua Rantau Wilayah Kerja Puskesmas Banua Lawas Kabupaten Tabalong Tahun 2019

Berdasarkan tabel 2 dapat dilihat bahwa dari 52 responden yang memiliki tingkat pendidikan rendah sebanyak $41 \quad(51,3 \%)$ responden tidak memiliki jamban, $6(7,5 \%)$ responden memiliki jamban yang tidak sehat, dan 5 (6,3\%) responden memiliki jamban sehat. Sedangkan dari 28 responden yang memiliki tingkat pendidikan tinggi sebanyak 11 $(13,8 \%)$ responden tidak memiliki jamban, $3(3,8 \%)$ responden memiliki jamban tidak sehat, dan 14 $(23,8 \%)$ responden memiliki jamban sehat. Hasil uji chi-square diperoleh bahwa variabel tingkat pendidikan menunjukkan ada hubungan yang bermakna dengan kepemilikan jamban keluarga dengan $p$ value $=0,000<\mathrm{a}(0,05)$.

Pendidikan akan mempengaruhi tingkat pengetahuan responden. Dimana semakin tinggi tingkat pendidikan seseorang maka tingkat pengetahuannya juga akan semakin baik, begitu pula sebaliknya, terutama pengetahuan responden mengenai jamban yang memenuhi syarat kesehatan dan tidak memenuhi syarat kesehatan. Rendahnya pendidikan responden juga di pengaruhi oleh tingkat penghasilan responden yang pada umumnya memiliki penghasilan di bawah UMK Kabupaten Tabalong tahun 2019, karena pada umumnya sebagian besar responden bekerja pada sektor informal yaitu sebagai petani (petani karet, petani padi, dan petani sayuran), sehingga belum mampu untuk membangun jamban keluarga.

Hubungan Status Pekerjaan Dengan Kepemilikan Jamban Keluarga di Desa Banua Rantau Wilayah Kerja Puskesmas Banua Lawas Kabupaten Tabalong Tahun 2019

Berdasarkan tabel 2 dapat dilihat dari 55 responden yang memiliki status pekerjaan informal sebanyak 44 (55\%) responden tidak memiliki jamban, $7(8,8 \%)$ responden memiliki jamban tidak sehat, dan $4 \quad(5,0 \%)$ responden memiliki jamban sehat. Sedangkan dari 25 responden yang memiliki status pekerjaan formal sebanyak $8(10 \%)$ responden tidak memiliki jamban, $2(2,5 \%)$ responden memiliki jamban tidak sehat, dan 15 (18,8\%) responden memiliki jamban sehat. Berdasarkan hasil uji statistik dengan Chi-Square menunjukkan $p$ value $0,000<a$ $(0,05)$ artinya bahwa ada hubungan yang bermakna antara status pekerjaan dengan kepemilikan jamban keluarga.

Status pekerjaan akan mempengaruhi tingkat penghasilan responden. Berdasarkan hasil penelitian 
$44(55 \%)$ responden yang tidak memiliki jamban keluarga bekerja dibidang sektor informal (petani padi, petani karet, dan petani sayuran) yang memiliki penghasilan tidak menentu setiap bulannya. Akan tetapi, ada juga responden yang bekerja dibidang sektor formal sebanyak $8(10 \%)$ belum memiliki jamban keluarga, responden tersebut memberikan alasan karena untuk sekarang jamban keluarga bukan kebutuhan yang mendesak ada sungai untuk MCK (mandi, cuci, dan kakus) yang tidak jauh dari rumah. Hal ini sejalan dengan penelitian Tarigan (2010), bahwa ada hubungan antara status pekerjaan dengan kepemilikan jamban di Kelurahan Pekan Selesei Kecamatan Selesei Kabupaten Langkat (5).

\section{Hubungan Tingkat Penghasilan Dengan Kepemilikan Jamban Keluarga di Desa Banua Rantau Wilayah Kerja Puskesmas Banua Lawas Kabupaten Tabalong Tahun 2019}

Berdasarkan tabel 2 dapat dilihat dari 47 responden yang memiliki tingkat penghasilan rendah sebanyak $41 \quad(51,3 \%)$ responden tidak memiliki jamban, $3(3,8 \%)$ responden memiliki jamban tidak sehat, dan $3(3,8 \%)$ responden memiliki jamban sehat. Sedangkan dari 33 responden yang memiliki penghasilan tinggi sebanyak $11(13,8 \%)$ responden tidak memiliki jamban, $6(7,5 \%)$ responden memiliki jamban tidak sehat, dan 19 (23,8\%) responden memiliki jamban sehat. Dari hasil analisis statistik menunjukkan ada hubungan yang bermakna antara tingkat penghasilan dengan kepemilikan jamban dengan uji statistik Chi-Square menunjukkan $p$ value $0,000<a(0,05)$.

Penghasilan kepala keluarga yang dimaksud dalam penelitian ini adalah suatu tingkat penghasilan yang diperoleh atau didapatkan per bulan dari hasil pekerjaan utama maupun pekerjaan sampingan, yang disesuaikan dengan besarnya Upah Minimum Kabupaten (UMK) Kabupaten Tabalong tahun 2019 yaitu sebesar Rp. 2.739.500,-. Responden yang memiliki penghasilan rendah akan sulit untuk membangun jamban keluarga, walaupun responden tersebut sudah memiliki pengetahuan yang baik tentang manfaat dan pentingnya jamban bagi keluarga dan kesehatan. Hal ini dikarenakan penghasilan yang diperoleh lebih diperuntukkan untuk memenuhi kebutuhan hidup sehari-hari, sehingga tidak cukup untuk membangun jamban keluarga, terutama jamban yang memenuhi syarat kesehatan. Sebagian responden yang memiliki penghasilan rendah di bawah UMK Kabupaten

Tabalong tahun 2019, juga sudah ada yang memiliki jamban sehat sebanyak 3 orang $(3,8 \%)$ responden. Mereka memberikan alasan bahwa mereka sudah paham akan penting dan manfaat memiliki jamban keluarga bagi kesehatan keluarga dan lingkungan. Tetapi, pada responden yang memiliki penghasilan tinggi sebanyak 11 orang $(13,8 \%)$ responden, mereka kebanyakan memberikan alasan kalau jamban bukan hal yang mendesak untuk dibangun dirumah karena ada sungai yang dekat dari rumah untuk MCK (mandi, cuci, dan kakus), masih banyak hal lain yang lebih diperlukan untuk dibeli. Masih banyak responden yang belum paham akan pentingnya jamban keluarga untuk kesehatan dan kebersihan lingkungan. Notoatmodjo (2007), dalam bukunya menyatakan pendapatan keluarga menentukan ketersediaan fasilitas kesehatan yang baik. Semakin tinggi pendapatan keluarga, semakin baik fasilitas dan cara hidup mereka yang terjaga akan semakin baik. Pendapatan merupakan faktor yang menentukan kualitas dan kuantitas fasilitas kesehatan di suatu keluarga (6).

Supraptini (2004) menyatakan, status ekonomi dapat mempengaruhi penyediaan jamban. Secara umum dapat dikatakan, semakin miskin rumah tangga semakin kecil persentase untuk menyediakan jamban keluarga sebaliknya semakin tinggi status ekonomi semakin besar persentase untuk menyediakan jamban keluarga (7). Hal ini sejalan dengan penelitian penelitian Febriwanti (2010) tentang hubungan karakteristik kepala keluarga dengan tingkat kepemilikan jamban di Kelurahan Bener di Kecamatan Tegal Rejo Kota Yogyakarta dimana didapati bahwa ada hubungan yang bermakna antara pendapatan dengan kepemilikan jamban (8).

Hubungan Pengetahuan Kepemilikan Jamban Keluarga di Desa Banua Rantau Wilayah Kerja Puskesmas Banua Lawas Kabupaten Tabalong Tahun 2019

Berdasarkan tabel 2 dapat dilihat dari 48 responden yang memiliki pengetahuan kurang sebanyak $43(53,8 \%)$ responden tidak memiliki jamban, $3(3,8 \%)$ responden memiliki jamban tidak sehat, dan $2(2,5 \%)$ responden memiliki jamban sehat. Sedangkan dari 32 responden yang memiliki 
pengetahuan baik sebanyak $9(11,3 \%)$ responden tidak memiliki jamban, $6(7,5 \%)$ responden memiliki jamban tidak sehat, dan $17(21,3 \%)$ responden memiliki jamban sehat. Berdasarkan hasil Uji statistik dengan Chi-Square menunjukkan $p$ value $0,000<a$ $(0,05)$, artinya bahwa ada hubungan yang bermakna antara pengetahuan dengan kepemilikan jamban keluarga.

Tingginya presentase pengetahuan kurang responden tentang jamban keluarga dipengaruhi oleh tingkat pendidikan, dimana dalam penelitian ini tingkat pendidikan responden lebih banyak yang masih berpendidikan rendah $41(51,3 \%)$ responden. Selain itu juga disebabkan karena kurangnya informasi yang diperoleh responden tentang pentingnya memiliki jamban keluarga, jenis jamban yang memenuhi syarat kesehatan, serta dampak bagi keluarga dan kesehatan jika tidak buang air besar di jamban. Hal tersebut bisa dilihat dari hasil kuesioner pertanyaan yang diisi oleh responden pada soal nomor 3 tentang apa saja penyakit yang akan ditimbulkan akibat buang air besar sembarangan, dari 80 (100\%) responden, hanya 37 (46,2\%) responden yang menjawab benar. Sama halnya dengan pertanyaan nomor 4 tentang apa saja penyakit yang dapat ditularkan melalui tinja (kotoran), dari $80(100 \%)$ responden hanya 34 (42,5\%) yang memberikan jawaban benar, dan pertanyaan tentang pengetahuan nomor 8 bagaimana jenis jamban sehat yang dianjurkan dalam kesehatan lingkungan, merupakan pertanyaan yang paling sedikit responden yang menjawab benar, yaitu hanya $20(25,0 \%)$, sisanya $60(75,0 \%)$ responden menjawab salah.

Dari hasil penelitian tentang pengetahuan masyarakat tentang jamban, terlihat bahwa pengetahuan responden mengenai penyakit yang ditimbulkan oleh tinja, manfaat jamban keluarga, dan syarat/standar bangunan jamban yang memenuhi syarat kesehatan masih rendah. Banyak responden yang belum mengetahui tentang manfaat jamban bagi kesehatan, hal ini juga dikarenakan kebiasaan responden yang masih menggunakan sungai sebagai tempat MCK (mandi, cuci, dan kakus) karena lokasi sungai tersebut tidak berada jauh dari rumah. Banyak responden tidak mengetahui bahwa buang air besar disungai dapat merugikan kesehatan dan juga lingkungan. Seperti dapat menjadi sumber penyakit, contohnya penyakit diare. Hal ini karena responden beranggapan bahwa selama mereka menggunakan sungai sebagai keperluan MCK (mandi, cuci, dan kakus) tidak pernah ada yang mengalami diare, sehingga masih ada responden yang beranggapan bahwa $\mathrm{BAB}$ disungai tidak menyebabkan penyakit. Hal ini juga yang menyebabkan sebagian responden yang sudah memiliki jamban, tetapi masih tetap BAB disungai (9)

Adapun responden yang memiliki pengetahuan baik yang belum memiliki jamban sebanyak $9(11,3 \%)$ responden, mengaku kalau belum ada cukup uang untuk membangun jamban di rumahnya. Menurut teori Notoatmodjo (2007), pengetahuan adalah merupakan hasil dari tahu, dan ini terjadi setelah seseorang melakukan pengindraan terhadap sesuatu objek tertentu, pengindraan terjadi melalui indera manusia yakni indera penglihatan, pendengaran, penciuman, rasa dan bau. Pengetahuan kesehatan akan berpengaruh pada perilaku kekeluargaan dan selanjutnya perilaku kesehatan akan berpengaruh pada meningkatnya indikator keKeluargaan masyarakat. Pengetahuan yang rendah sangat berpengaruh terhadap penyediaan jamban jika dibanding dengan kepala keluarga yang berpengetahuan tinggi (6).

Hal ini sejalan dengan penelitian Darsana (2012) tentang Faktor-Faktor yang Berhubungan dengan Kepemilikan Jamban Keluarga di Desa Jehem Kecamatan Tembuku Kabupaten Bangli Tahun 2012 dimana didapati bahwa ada hubungan yang bermakna antara pengetahuan dengan kepemilikan jamban keluarga (10). Dari hasil penelitian tentang pengetahuan masyarakat tentang manfaat kepemilikan jamban dari 90 responden, yang memiliki pengetahuan baik tentang manfaat jamban sebanyak 49 orang $(54,4 \%)$ dan yang memiliki pengetahuan tidak baik sebanyak 41 orang $(45,6 \%)$. Untuk itu diperlukan upaya yang lebih serius dari pihak Puskesmas, Kepala Desa, dan Pihak Dinas Kesehatan dalam meningkatkan pengetahuan dan kesadaran seluruh masyarakat di Desa Banua Rantau tentang jamban sehat, sehingga kesadaran seluruh anggota keluarga akan pentingnya jamban bisa lebih baik. 


\section{KESIMPULAN DAN SARAN}

Hasil penelitian terhadap 80 responden yang menjadi sampel penelitian dari jumlah keseluruhan kepala keluarga sebanyak 437 KK. Hasil penelitian yang diperoleh bahwa sebagian besar responden berpendidikan rendah 52 (65\%), sebagian besar responden bekerja di bidang sektor informal 55 $(68,8 \%)$, sebagian besar responden berpenghasilan rendah $47(58,8 \%)$, sebagian besar responden memiliki pengetahuan rendah $48(60 \%)$, sebagian besar responden tidak memiliki jamban keluarga 52 (65\%) responden, ada hubungan yang bermakna antara tingkat pendidikan, status pekerjaan, tingkat penghasilan, dan pengetahuan dengan kepemilikan jamban keluarga di Desa Banua Rantau Wilayah Kerja Puskesmas Banua Lawas Kabupaten Tabalong Tahun 2019. Bagi petugas kesehatan khususnya petugas kesehatan lingkungan di wilayah kerja Puskesmas Banua Lawas agar meningkatkan penyuluhan kesehatan mengenai pentingnya kepemilikan jamban keluarga dan sanitasi lingkungan untuk mencegah terjadinya penularan penyakit akibat lingkungan serta menjaga lingkungan agar tetap bersih, diharapkan kepada Dinas Kesehatan Kabupaten Tabalong agar membangun jamban umum (jamban komunal) sebagai sarana/ tempat untuk buang air besar bagi masyarakat yang belum mampu untuk membangun jamban keluarga, dan bagi peneliti selanjutnya diharapkan agar bisa melakukan penelitian lebih lanjut mengenai faktor-faktor yang berhubungan dengan Kepemilikan Jamban Keluarga selain variabel yang sudah diteliti seperti faktor lainnya seperti ketersediaan lahan, ketersediaan air bersih, dan peran petugas kesehatan.

\section{UCAPAN TERIMAKASIH}

Penulis mengucapkan terimakasih kepada Universitas Islam Kalimantan MAB Banjarmasin Bagian Lembaga Penelitian dan Pengabdian Kepada Masyarakat (LPPM) selaku pemegang anggaran penelitian dan pemberi izin dan Puskesmas Puskesmas Banua Lawas Kabupaten Tabalong selaku pemberi izin dan pemberi data serta informasi data yang dibutuhkan dalam penelitian sehingga kegiatan penelitian ini dapar berjalan dengan baik.

\section{DAFTAR PUSTAKA}

1. WHO. 2015. Progres Sanitasi dan Air MinumProgress on Sanitation and Drinking-Water: Update. Geneva: WHO 2010. Official Websita diakses pada laman http:www.unicef.org/Indonesia/id/A8-

B.Ringkasan-Kajian-AirBersih.pdf. [diakses 02 maret 2019]

2. Yance Warman,. 2006. Faktor-Faktor Yang Berkaitan dengan Perilaku Masyarakat Dalam Pemanfaatan Jamban Keluarga Di Kelurahan Gonoharjo Kecamatan Limbangan Kabupaten Dati II Kendal Propinsi Dati I Jawa Tengah.

3. Pane, Erlinawati. 2009. Pengaruh Perilaku Keluarga terhadap Penggunaan Jamban. http://journal.fkm.ui.ac.id/kesmas/article/view/215/2 15

4. Lameshow, S, dkk. Besar Sampel Dalam Penelitian Kesehatan. Jogjakarta: Gajahmada University Press

5. Tarigan, R. 2010. Hubungan Karakteristik, Pengetahuan, dan Sikap Kepala Keluarga Dengan Kepemilikan Rumah Sehat di Kelurahan pekan Selesei Kecamatan Selesei Kabupaten Langkat Tahun 2010. Universitas Sumatera Utara: Fakultas Kesehatan Masyarakat.

6. Notoadmodjo, S. 2007. Promosi Kesehatan dan Ilmu Perilaku. Jakarta: Rineka Cipta.

7. Supartini, Y. 2004. Buku Ajar Konsep Dasar Keperawatan Anak. Jakarta: EGC.

8. Febriwanti. 2010. Hubungan Kepemilikan Jamban dengan Kejadian Diare di Kelurahan Bener di Kecamatan Tegal Rejo Kota Yogyakarta Tahun 2010.

9. Darsana, N. 2012. Faktor-Faktor Yang Berhubungan Dengan Kepemilikan Jamban Keluarga di Desa Jehem kecamatan Tembuku Kabupaten Bangli Tahun 2012. Poltekes Denpasar: Kesehatan Lingkungan

10. Azwinsyah, dkk. 2014. Faktor-Faktor yang Berhubungan dengan Rendahnya Kepemilikan Jamban Keluarga dan Personal Hygiene dengan Kejadian Diare di Desa Sei Musam Kendit Kecamatan Bahorok Kabupaten Langkat Tahun 2014. http://download.portalgaruda.org/ [diakses 01 maret 2019]. 